\title{
Fundamentos para uma Política Nacional de Prevenção e Controle do Câncer
}

\author{
Rationale for a National Cancer Prevention and Control Policy
}

A preocupação com a prevenção e controle do câncer, tomando-o como um problema de saúde pública, iniciou-se nos anos 30 por um grupo de médicos liderado pelo Prof. M ário K röeff. N aquela época, já se idealizava uma "ampla política sanitária de combate ao câncer", de âmbito nacional, que fosse capaz de orientar as ações preventivas e assistenciais em larga escala e corrigindo a tendência, que também já se verificava, no Brasil, de se priorizar as ações terapêuticas individuais, levadas a cabo nos ambientes médicohospitalares.

Porém, uma evolução efetiva nesse sentido não se deu até 1986, quando o M inistério da Saúde, no âmbito da ainda existente Campanha $\mathrm{N}$ acional de Combate ao Câncer (que havia sido criada em 1967), passou a desenvolver ações descentralizadas nas áreas da informação (registros de câncer), prevenção (controle do tabagismo e do câncer do colo uterino) e educação em O ncologia.

Com a promulgação da Constituição de 1988 e a criação do Sistema Ú nico de Saúde (SUS), regulamentada pela Lei O rgânica da Saúde, a 8.080, de 19 de setembro de 1990, estruturas regimentais foram atualizadas e, também em termos da prevenção e controle do câncer, as novas diretrizes vieram reforçar e ampliar aquelas ações.

O s seguidos decretos presidenciais que estabeleceram o Regimento do M inistério da Saúde (o D ecreto 109, de 05 de maio de1991; o D ecreto 2.477, de 28 de janero de 1998; e 0 D ecreto 3.496 , de $1^{\circ}$ de junho de 2000 , em vigência) atribuem ao Instituto $\mathrm{N}$ acional de Câncer (IN CA), como órgão próprio e sua instância técnica, "assistir o M inistro de Estado na formulação da política nacional deprevenção, diagnóstico e tratamento do câncer".
Todas as iniciativas passaram, assim, a ter como diretriz maior a própria formulação de uma Política $\mathrm{N}$ acional de Prevenção e Controle do Câncer (PN PCC).

Investimentos específicos se deram, e continuam se dando, por meio de convênios assinados com as secretarias estaduais de saúde, para estas desenvolverem, do ponto de vista gerencial e operacional, e sob a assessoria técnico-gerencial contínua do M inistério da Saúde, os programas de implantação de registros de câncer (de base hospitalar e de base populacional), de controle do tabagismo e de controle do câncer do colo uterino e de mama, os dois últimos estruturados nas secretarias municipais de saúde.

Com base no trabalho desenvolvido em todas as áreas e em todos os níveis do conhecimento e da administração de ações de prevenção e controle do câncer do colo uterino, até 1998, pôs-se em curso, nesse ano, a maior mobilização de mulheres e do sistema de saúde brasileiro para a prevenção, diagnóstico precoce e tratamento deste tumor e de suas lesões precursoras, com a realização de mais de 03 milhões de exames preventivos e a detecção e tratamento de mais de 10 mil mulheres. I nvestida similar será feita também em 2002.

Em 1999, deu-se início à estruturação funcional e técnico-gerencial para o controle do câncer de mama, inclusive com a aquisição e destinação de mamógrafos a instituições públicas e filantrópicas, pelo $M$ inistério da Saúde, e, à semelhança do que se deu para o programa de prevenção e controle do câncer do colo uterino, treinamento de recursos humanos em todo o Brasil, sob a coordenação do INCA. 
No campo da formação de recursos humanos, em praticamente todas as profissões, níveis e especialidades essenciais para a prevenção e assistência oncológica, os investimentos também vêm sendo crescentes, tendo o M inistério da Saúde, por meio do IN C A, aumentado, de 1998 para cá, a oferta de vagas regulares em mais de 63\% (de 241 para 394).

A regulamentação técnico-gerencial e a descentralização progressiva, na área da assistência oncológica, foram operacionalizadas a partir das portarias ministeriais 3.535 (estruturação dos serviços oncológicos e reorganização do nível terciário no sistema de al ta complexidadeem 0 ncologia), a 3.536 (novas regras para autorização, cobrança e pagamento de procedimentos quimioterápicos e radioterápicos), ambas de 02 de setembro de 1998, e todas as que se seguiram a elas relacionadas.

O utras iniciativas de maior relevância para a reestruturação do nível terciário, o da assistência especializada oncológica propriamente dita, podem ser exemplificadas pelo desenvolvimento de projetos e programas que buscam a melhoria assistencial e gerencial, como o Projeto ReforSus, o Programa dos $\mathrm{C}$ entros Colaboradores, 0 Projeto de Reequipamento Hospitalar, o Projeto Expande e o Programa de Q ualidade em Radioterapia.

$\mathrm{N}$ a área de transplante de medula óssea, a portaria ministerial 1.217, de 1999, reorientou o cadastramento de serviços e criou novos procedimentos, inclusive os de inclusão de doadores no Registro $\mathrm{N}$ acional de D oadores Voluntários de M edula Ó ssea e os de busca nacional e internacional de doadores; e as portarias, também ministeriais, numeradas de 1.312 a 1.317 , de 2000, ampliaram todos os aspectos técnicos, gerenciais e operacionais do sistema para esse tipo de transplante - sendo que uma nova revisão encontra-se em curso, no sentido de melhorar cada vez mais a organização e 0 acesso a esse sistema.

M esmo com tudo isso ocorrendo, a necessidade de formalização da PN PCC já vinha sendo identificada há al gum tempo pelo M inistério da Saúde.

$\mathrm{N}$ a sequência de diversos trabalhos feitos em anos anteriores, a Secretaria de Políticas de Saúde (SPS) do M inistério da Saúde formou, em 1999, um grupo de especialistas do M inistério, inclusive o IN CA, e de outras instituições ligadas à problemática do câncer, para elaborar uma versão de política que seria submetida a diversas instâncias, até a sua adoção pelo Governo Brasileiro.

Essegrupo elaborou uma anál ise de situação, que pudesse servir de exposição de motivos, e um esboço de diretrizes para essa política.

$\mathrm{N}$ a reordenação das atividades da SPS, os trabalhos relativos à PN PCC passaram para a Secretaria de Assistência à Saúde (SAS), também do M inistério da Saúde, que solicitou ao INCA a continuação e a atualização dos conceitos até então elaborados.

0 que se segue representa essa atual ização.

\section{Panorama Geral}

A situação do câncer, no Brasil, resultou da análise, por parte do grupo e de outros especialistas, no IN CA e fora dele, de diversos documentos, especialmente epidemiológicos, e das experiências e vivências de quem trabalha no setor há muitos anos.

O s quatro pontos a seguir são uma síntese dessa etapa do trabalho, e representam, em termos executivos, os el ementos básicos que caracterizam a necessidade de uma política pública. Eles explicitam a dimensão do problema e a sua tendência crescente, identificam a inadequação dos serviços oncológicos e a importância do equilíbrio entre prevenção e terapêutica: 1) o câncer é a segunda causa de mortalidade por doença, no Brasil; 2) a incidência de câncer cresce progressivamente, inclusive em faixas etárias abaixo dos 50 anos; 3) os serviços de assistência oncológica são insuficientes, às vezes inadequados e mal distribuídos geograficamente; e4) muitos óbitos poderiam ser evitados por ações de prevenção ou detecção precoce.

Este panorama é agravado por circunstâncias conjunturais, que extrapolam a área da oncologia ou mesmo da Saúde, e que reforçam a necessidade de uma política nacional para a prevenção e o controle do câncer no Brasil: desatualização técnico- 
científica, informação gerencial e epidemiológica incipiente e recursos humanos insuficientes em quantidade e qualidade.

A participação de outros ministérios, dos estados e municípios e da sociedade em geral, organizada ou não, definem a abrangência a ser dada a essa política.

Também fica evidente a importância da pesquisa, da informação e do ensino, como áreas de apoio que, junto com as áreas finalísticas de prevenção e assistência, dão às ações de prevenção e controle do câncer câncer um enfoque de integralidade.

Pelo exposto, conclui-se que o câncer é um problema de saúde pública e requer uma política nacional para sua prevenção e controle.

\section{Objetivo da PNPCC}

0 objetivo da política deve referir-se, simultaneamente, às questões relativas à incidência e à mortalidade por câncer.

A redução da incidência está diretamente associada às medidas de prevenção e de conscientização da população quanto aos fatores de risco de câncer. Já a redução da mortalidade depende da capacidade nacional em detectar 0 câncer, o mais precocemente possível, e tratá lo adequadamente. Estas duas ações, além de caracterizarem a indissolubilidade do binômio prevenção-assi stência, prevêem a aplicação dessas ações em âmbito nacional e de forma universal.

\section{Situação Desejada}

A situação desejada é a que permite 0 alcance do objetivo.

Por se tratar de objetivo permanente, ou seja, por ser sempre possível procurar redução maior de incidência ou mortalidade por câncer, pode-se idealizar uma situação em que um conjunto de ações, estabelecidas em todo o território nacional e para toda a população, abordem, continuamente, a prevenção e 0 controle do câncer.

Essas ações devem contemplar, também, a pesquisa, o ensino e a informação, pois todos estão implicitamente associados à idéia da qualidade do tratamento.

"Ter um conjunto de ações, estabelecidas e contínuas, que levem à conscientização da população quanto aos fatores de risco de câncer, que promovam a detecção precoce do câncer e que dêem acesso a um tratamento de qualidade, equitativo e em todo o território nacional" seria a situação desejada, que pode ser colocada em forma de diretrizes que permitam orientar as diversas instituições pertinentes na elaboração de programas, projetos ou ações, em cada aspecto considerado pela PN PCC.

Especificamente, os aspectos de prevenção, detecção precoce, assistência, qualidade, abrangência e equitatividade devem estar presentes nessas diretrizes.

\section{Diretrizes}

Sendo diretrizes de política, também devem ser suficientemente abrangentes para serem válidas por longo período e, ao mesmo tempo, deixar clara a direção geral que deverá balisar as ações de prazo mais curto.

As quatro diretrizes abaixo são o resultado dessas considerações: 1) estabelecer, em âmbito nacional, ações de prevenção do câncer, visando à promoção da saúde do povo brasileiro; 2) detectar precocemente os cânceres passíveis de tal detecção, para aumentar a probabilidade de cura e melhorar a qualidade de vida dos(as) doentes; 3) consolidar e expandir os serviços de assistência oncológica, equitativamente, em todo o país, e de forma integrada; e 4) promover o desenvolvimento de recursos humanos, de estudos, pesquisas, e outras ações indispensáveis à qualidade desejada de serviços e ações de prevenção e controle do câncer.

\section{Estratégias de Execução}

A execução das diversas políticas de controle de câncer, no mundo, depende consideravelmente do estágio de desenvolvimento de cada país e de suas particularidades territoriais, sócio-culturais e econômicas.

As estratégias vão desde uma forte centralização, necessidade de liderança pessoal e dependência de recursos estatais e externos, em países em estágios iniciais de desenvolvimento, 
até uma coordenação tênue, descentralização e orientação para 0 atendimento à demanda e incorporação tecnológica para manter a produção de bens e 0 consumo de produtos, em países desenvolvidos.

No Brasil, a dimensão territorial, a estrutura de saúde pública e os fatores sócioeconômicos da sua população são condicionantes de uma estratégia própria e que se adeqüe às condições nacionais.

O s elementos essenciais da estratégia brasileira para a execução da PN PCC estão colocados a seguir:

\section{Coordenação centralizada}

o M inistério da Saúde coordena, em âmbito nacional, as ações de prevenção e controle do câncer. Contribuem para a necessidade de uma coordenação centralizada, a heterogeneidade regional do Brasil, em termos econômicos, sociais e culturais, e a distribuição desigual de serviços de saúde.

0 fato de o SUS atender mais de dois terços da população, inclusive na área de câncer, reforça essa situação.

Foi para operacionalizar essa coordenação, que o M inistério da Saúde atribuiu a função ao seu órgão setorial, o Instituto $\mathrm{N}$ acional de Câncer, 0 que foi ratificado através dos já citados sucessivos decretos presidenciais.

0 INCA deve exercer essa coordenação, apoiado em sua base técnica de serviços e programas.

\section{Estrutura Pública de Saúde}

O SUS, além de atender a grande maioria dapopulação, conforme citado, foi fundamental para estruturar esse atendimento: pela Lei 8.080/90, estabeleceram-se os diversos níveis de gestão, o federal, o estadual e o municipal, e definiram-se as responsabilidades de cada um desses níveis.

Com isso ficou estabelecida uma lógica de funcionamento para a execução descentralizada dos serviços de saúde em qualquer estado e município brasileiros.

\section{Ações descentralizadas}

A lógica do SUS obriga os estados e municípios a se estruturarem e descentralizarem os seus serviços de saúde. A mesma lógica é aplicada, também, às atividades de prevenção, detecção precoce e assistência ao doente com câncer.

Com ações descentralizadas, também fica facilitada a interiorização das ações de prevenção e controle do câncer, pois a descentralização chega ao nível dos municípios.

Por outro lado, a coordenação centralizada, apoiada em atos normativos pertinentes, atuando conforme a lógica do SU S e chegando até os municípios, permite operacionalizar os programas de prevenção e tornar adequado 0 atendimento ao doente com câncer. Essa operacionalizar deve estimular a integralidade assistencial dos serviços básicos, preventivos, e dos serviços especial izados, terapêuticos estes últimos integrados nos Centros de Alta Complexidade em O ncologia (CACON).

U ma forma de atender as exigências dessa estrutura, quando não há condições locais, é através da criação de parcerias, dentro dos estados, entre os estados e, destes, com o gestor federal. Essas parcerias podem extrapolar a área assistencial e incentivar as demais atividades que completam o enfoque de integralidade das ações de prevenção e controle do câncer.

Os elementos essenciais das ações descentralizadas são, portanto: 1) interiorização; 2) integralidade das ações de prevenção e controle do câncer; 3) integração de serviços assistenciais; e 4) parcerias.

Recursos governamentais

$\mathrm{N}$ as atividades e serviços referentes à prevenção e controle do câncer, a principal fonte de recursos financeiros vem do orçamento da União, através do M inistério da Saúde. A contribuição financeira da iniciativa privada é pequena, assim como recursos provenientes do exterior.

O SUS, com a sua característica de universalidade, recebe a principal parcela desse orçamento. Isto, mais do que um fato, é uma necessidade ditada pela conjuntura atual do Brasil. É pouco provável que estas condições possam mudar a curto ou médio prazo, obrigando considerar o forte aporte de recursos governamentais, como elemento indispensável da estratégia brasileira. 
Ações normativas

Considerando-se a descentralização e 0 grande aporte de recursos governamentais, toda a estratégia só pode funcionar adequadamente com um conjunto de ações normativas, de responsabilidade do M inistério da Saúde e que disciplinem a execução de ações, em qualquer lugar no país.

Esta regulamentação deve apoiar-se em instrumentos legislativos e incluir todas as ações existentes. $D$ eve, também, prover 0 acompanhamento e a avaliação dos programas e atividades em curso para corrigir rumos e eliminar desvios.

Em síntese, pode-se assim explicitar como elementos básicos da ações normativas: 1) instrumentos legislativos; 2) atividades de regulação e 3) acompanhamento e avaliação.

\section{Prioridades}

As prioridades, que decorrem das diretrizes da PN PCC, focalizam, dentro da orientação geral dada pelas diretrizes, linhas mais específicas de ação. Essas linhas são importantes, tanto para a formulação de planos plurianuais de Governo, como para orientar no planejamento de ações por parte de gestores.

Pela situação descrita em Panorama Geral e pela Situação D esejada definida, as seguintes prioridades ficariam justificadas: 1) estabelecer, em âmbito nacional, programas de controle dos fatores de risco de câncer (tabagismo, fatores alimentares, exposição às radiações); 2) estabelecer, em âmbito nacional, programas de detecção precoce de cânceres do colo do útero, mama, pele e boca; 3) propiciar condições para a prestação de serviços assistenciais integrados e expandi-los nacionalmente; 4) estabelecer mecanismos de regulação de fluxo de pacientes em âmbitos estadual e regional; 5) estabelecer sistemas de avaliação e vigilância do câncer e de seus fatores de risco; e 6) estabelecer, em âmbito nacional, programas de qualificação de recursos humanos e de pesquisas básicas, clínicas e epidemiológicas.

\section{Considerações Finais}

M uito se precisou fazer, nas duas últimas décadas, para que o país pudesse dispor de dados, parâmetros e de mecanismos para superar um dos seus maiores desafios: estruturar e desenvolver o SU S, identificar problemas e priorizar soluções, ao mesmo tempo em que buscava planejar políticas públicas e a assistência à saúde.

Com o esforço de gerações, desenhou-se para o Brasil uma PN PCC que, atualmente, exige formalização documental para se consolidar, após ser adequadamente apresentada, analisada, melhorada e divulgada nos foros pertinentes (a C omissão Intergestora Tripartite do SU S e o Conselho Nacional de Saúde, para começar).

Para avançar nesse sentido, há de se ter em mente que Política é um instrumento de Estado, que deve ser o mais abrangente para ser duradoura, ultrapassar os limites de governos e aten der as aspirações da Sociedade, ao longo do tempo. E que da Política saem as prioridades que, traduzidas em ações, projetos e programas e seus respectivos orçamentos e gastos, configuram o Plano Plurianual, este um instrumento de Governo.

Q ue o trabal ho de tanta gente e de tantos anos tenha um futuro profícuo e alentador para todos nós, brasileiros.

Jacob Kligerman

Diretor Geral do

Instituto $\mathrm{N}$ acional de $\mathrm{C}$ âncer

M inistério da Saúde 